\title{
LETTER
}

\section{Size distribution of ferrihydrite aggregate and its implication for metal adsorption and transport}

\author{
Haruka TsuBAKI $^{*, * *}$, Takumi SAITo ${ }^{* * *}$ and Takashi MuRAKAMI \\ *Department of Earth and Planetary Science, the University of Tokyo, \\ 7-3-1 Hongo, Bunkyo-ku, Tokyo 113-0033, Japan \\ ***esent address: Nihon Waters K.K., 1-3-12 Kitashinagawa, \\ Shinagawa-ku, Tokyo 140-0001, Japan \\ *** Department of Nuclear Engineering and Management, the University of Tokyo, \\ 7-3-1 Hongo, Bunkyo-ku, Tokyo 113-8656, Japan
}

\begin{abstract}
Adsorption experiments of $\mathrm{Zn}$ onto ferrihydrite were carried out at different initial Fe concentrations and $\mathrm{pH}$, and at room temperature. Zinc-adsorbed ferrihydrite was fractionated to examine $\mathrm{Zn}$ adsorption among different-size aggregates of ferrihydrite. Primary ferrihydrite particles were as small as 5-7 nm in diameter and they formed aggregates of $<0.25$ to $>32 \mu \mathrm{m}$ in size. The dominant size of the aggregates decreased with a decrease in the initial Fe concentrations and $\mathrm{pH}$. Zinc was adsorbed on the surface of individual ferrihydrite nano-particles but not on that of ferrihydrite aggregates, indicating that ferrihydrite nano-particles were so loosely attached to one another in aggregates that individual nano-particles could adsorb $\mathrm{Zn}$. The size distribution of ferrihydrite aggregates and the $\mathrm{Zn}$ adsorption on individual ferrihydrite nano-particles can change the sedimentation rate of ferrihydrite aggregates and the behavior of $\mathrm{Zn}$ during the transformation of ferrihydrite to goethite and hematite. Therefore, our results will give a deeper understanding of metal transport by ferrihydrite.
\end{abstract}

Keywords: Ferrihydrite, Adsorption, Size distribution, Nano-particle, Metal transport

\section{INTRODUCTION}

Ferrihydrite is ubiquitous in natural environments and characterized by its nano-size, large specific surface area and high adsorption capacity; ferrihydrite is metastable and transformed to goethite and hematite, and further, it forms aggregate (e.g., Cornell and Schwertmann, 2003). Because of the important roles of ferrihydrite in element transport (e.g., Cornell and Schwertmann, 2003; Hassellöv and von der Kammer, 2008), the sorption onto ferrihydrite has been intensively investigated for both cations such as $\mathrm{Cu}, \mathrm{Zn}, \mathrm{Cd}, \mathrm{Pb}$ and $\mathrm{U}$ and anions such as $\mathrm{P}, \mathrm{As}$ and I (e.g., Scheinost et al., 2001; Waychunas et al., 2002; Trivedi et al., 2004; Song et al., 2008; Nagata et al., 2009; Rossberg et al., 2009; Antelo et al., 2010; Carabante et al., 2010; Rout et al., 2012). Ferrihydrite aggregates made from a solution of $\sim 0.2 \mathrm{mM} \mathrm{Fe}$ exhibits a significant size range from $<1 \mu \mathrm{m}$ to a few hundreds of $\mu \mathrm{m}$ (Lo and

doi:10.2465/jmps. 120618

H. Tsubaki, geologin_ht@yahoo.co.jp

T. Saito, takumi@ flanker.n.t.u-tokyo.ac.jp

T. Murakami, murakami@eps.s.u-tokyo.ac.jp Corresponding author
Waite, 2000). The sedimentation time depends on their size; for instance, it is estimated to take a few thousand days and a few days for 5- and 200-nm ferrihydrite aggregates, respectively, to sediment by $10 \mathrm{~mm}$ in depth (Tsukimura et al., 2010). Ferrihydrite particles can transport adsorbed elements when they are dispersed (Novikov et al., 2006). On the other hand, adsorbed elements can be immobilized if ferrihydrite aggregates sediment or if adsorbed elements form precipitates during the transformation of ferrihydrite to hematite and goethite (Murakami et al., 1997, 2005). For elemental transport, therefore, the size distribution of ferrihydrite particles and aggregates and the reaction pathways posterior to adsorption are important factors, in addition to adsorption itself.

The present study aimed to elucidate $\mathrm{Zn}$ adsorption among different-size aggregates of ferrihydrite, which can give deeper understandings of metal transport. Zinc was chosen for an adsorbate because it is simply adsorbed on the surface of ferrihydrite at less than tens of $\mu \mathrm{M}$ of $\mathrm{Zn}$ (Waychunas et al., 2002). 
Table 1. Experimental conditions and $\mathrm{Fe}$ and $\mathrm{Zn}$ concentration in fractions

\begin{tabular}{|c|c|c|c|c|c|c|c|c|c|c|c|}
\hline \multicolumn{3}{|c|}{ Run 1} & \multicolumn{3}{|c|}{ Run 2} & \multicolumn{3}{|c|}{ Run 3} & \multicolumn{3}{|c|}{ Run 4} \\
\hline \multirow{2}{*}{ 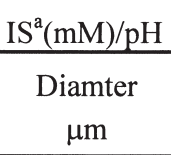 } & \multicolumn{2}{|c|}{$4.6 / 7.5$} & \multirow{2}{*}{$\begin{array}{c}\text { IS }(\mathrm{mM}) / \mathrm{pH} \\
\text { Diamter } \\
\mu \mathrm{m}\end{array}$} & \multicolumn{2}{|c|}{$4.5 / 7.0$} & \multirow{2}{*}{$\begin{array}{c}\text { IS }(\mathrm{mM}) / \mathrm{pH} \\
\begin{array}{c}\text { Diamter } \\
\mu \mathrm{m}\end{array} \\
\end{array}$} & \multicolumn{2}{|c|}{$4.4 / 4.2$} & \multirow{2}{*}{$\frac{\mathrm{IS}(\mathrm{mM}) / \mathrm{pH}}{\begin{array}{c}\text { Diamter } \\
\mu \mathrm{m}\end{array}}$} & \multicolumn{2}{|c|}{$7.6 / 7.0$} \\
\hline & $\begin{array}{c}\mathrm{Fe} \\
\mathrm{ppm}^{\mathrm{b}}\end{array}$ & $\begin{array}{c}\mathrm{Zn} \\
\mathrm{ppm}\end{array}$ & & $\begin{array}{c}\mathrm{Fe} \\
\mathrm{ppm}\end{array}$ & $\begin{array}{c}\mathrm{Zn} \\
\mathrm{ppm}\end{array}$ & & $\begin{array}{c}\mathrm{Fe} \\
\mathrm{ppm}\end{array}$ & $\begin{array}{c}\mathrm{Zn} \\
\mathrm{ppm}\end{array}$ & & $\begin{array}{c}\mathrm{Fe} \\
\mathrm{ppm}\end{array}$ & $\begin{array}{c}\mathrm{Zn} \\
\mathrm{ppm}\end{array}$ \\
\hline Initial $^{c}$ & 11.26 & 4.90 & Initial & 1.12 & 0.490 & Initial & 11.26 & 0.499 & Initial & 11.21 & 4.90 \\
\hline$<20$ & 10.26 & 5.32 & $<10$ & 0.84 & 0.412 & $<5$ & 9.12 & 0.494 & $<32$ & 9.79 & 5.20 \\
\hline$<10$ & 10.02 & 5.13 & $<7.5$ & 0.85 & 0.429 & $<3$ & 9.01 & 0.490 & $<16$ & 9.54 & 5.14 \\
\hline$<7.5$ & 9.84 & 5.09 & $<5$ & 0.82 & 0.415 & $<2$ & 9.40 & 0.503 & $<8$ & 7.78 & 4.80 \\
\hline$<5$ & 9.27 & 4.90 & $<3$ & 0.70 & 0.397 & $<1$ & 8.86 & 0.496 & $<4$ & 1.07 & 2.90 \\
\hline$<1.8$ & 2.99 & 2.52 & $<1.8$ & 0.65 & 0.389 & $<0.75$ & 7.48 & 0.442 & $<2$ & 0.25 & 2.45 \\
\hline$<0.5$ & 0.66 & 1.76 & $<0.75$ & 0.28 & 0.365 & $<0.5$ & 7.17 & 0.438 & & & \\
\hline$<0.25$ & 0.22 & 1.58 & $<0.5$ & 0.12 & 0.354 & $<0.3$ & 7.94 & 0.484 & & & \\
\hline & & & $<0.3$ & 0.04 & 0.358 & $<0.25$ & 6.62 & 0.486 & & & \\
\hline & & & $<0.25$ & 0.02 & 0.354 & & & & & & \\
\hline
\end{tabular}

${ }^{\text {a }}$ IS stands for ionic strength; the range of the present IS values does not change the $\mathrm{Zn}$ adsorption significantly (e.g., Trivedi et al., 2004).

${ }^{\mathrm{b}}$ The uncertainties of measurements by ICP-AES were $5 \%$ of relative standard deviation.

${ }^{\mathrm{c}}$ Concentrations before fractionation. The initial concentration of Fe was 0.2 or $0.02 \mathrm{mM}$ and that of $\mathrm{Zn} 75$ or $7.5 \mu \mathrm{M}$.

\section{EXPERIMENTAL}

Ferrihydrite was synthesized from a $\mathrm{Fe}\left(\mathrm{NO}_{3}\right)_{3}$ solution by adding $1 \mathrm{M} \mathrm{NaOH}$ solution until $\mathrm{pH}$ 7-8 and aged for 2 hours (modified from Davis and Leckie, 1978; Schwertmann and Cornell, 2000). Synthesized ferrihydrite was confirmed to be two-line ferrihydrite by $\mathrm{X}$-ray diffraction (XRD, data not shown). The morphology of ferrihydrite particles and aggregates were observed by transmission electron microscopy (TEM). The TEM sample was prepared from a solution made similar to experimental run 2 (Table 1) and passed through a $0.22 \mu \mathrm{m}$ membrane filter.

After adding a $1 \mathrm{M} \mathrm{NaNO}_{3}$ background electrolyte solution to aliquots of the ferrihydrite suspension, $\mathrm{Zn}\left(\mathrm{NO}_{3}\right)_{2}$ solution was poured to be $8-75 \mu \mathrm{M}$ of $\mathrm{Zn}$ in resultant solutions. The $\mathrm{pH}$ of the samples was adjusted by $0.01,0.1$ and $1 \mathrm{M}$ of $\mathrm{NaOH}$ and $\mathrm{HNO}_{3}$. The $\mathrm{Zn}$ adsorption reached equilibria in 2 hours (data not shown), and therefore, all adsorption experiments were conducted with more than 2-hour reaction time. All experiments were carried out in Ar atmosphere and at $22 \pm 1{ }^{\circ} \mathrm{C}$ of temperature. The experimental conditions are given in Table 1 .

Centrifugation was used to fractionate ferrihydrite aggregates (runs 1, 2 and 3 in Table 1). In addition, gravitational sedimentation was employed to fractionate larger aggregates (run 4 in Table 1). The suspension of $\mathrm{Zn}$-adsorbed ferrihydrite aggregates was dispersed ultrasonically for three minutes before fractionation. For fractionation by centrifugation, $45 \mathrm{~mL}$ of each lot of the suspension was centrifuged for an assigned time and rotation rate as given in Table 2, which were calculated based on the assumption that ferrihydrite particles and aggregates were spherical, the viscosity of the solution $1 \mathrm{~Pa}$ s, the density
Table 2. Conditions for centrifugation

\begin{tabular}{ccc}
\hline $\begin{array}{c}\text { Diamter } \\
\mu \mathrm{m}\end{array}$ & $\begin{array}{c}\text { Rotation time } \\
\min \end{array}$ & $\begin{array}{c}\text { Rotation per } \\
\min (\mathrm{rpm})\end{array}$ \\
\hline$<20$ & 1.15 & 400 \\
$<10$ & 5 & 400 \\
$<7.5$ & 9 & 400 \\
$<5$ & 4 & 900 \\
$<3$ & 11 & 900 \\
$<2$ & 2 & 3200 \\
$<1.8$ & 2.4 & 3200 \\
$<1$ & 7.9 & 3200 \\
$<0.75$ & 14 & 3200 \\
$<0.5$ & 31 & 3200 \\
$<0.3$ & 87 & 3200 \\
$<0.25$ & 125 & 3200 \\
\hline
\end{tabular}

of water $1.0 \mathrm{~g} / \mathrm{cm}^{3}$, and the density of ferrihydrite $3.96 \mathrm{~g} /$ $\mathrm{cm}^{3}$ (for 6-line ferrihydrite, Towe and Bradley, 1967). A supernatant was sampled after each centrifugation run. For fractionation by gravitational sedimentation, the suspension solution was put in a graduated cylinder of about $30 \mathrm{~cm}$ height and sampled with pipette from $5-\mathrm{cm}$ depth at assigned settling time calculated by Stokes law. Analytical grade $\mathrm{HNO}_{3}$ was added to the sampled solutions to dissolve all ferrihydrite. Then, the $\mathrm{Fe}$ and $\mathrm{Zn}$ concentrations of the solutions were measured by inductively coupled plasma atomic emission spectrometry (ICP-AES, Scientific Instruments, SPS-7700). The uncertainties of measurements by ICP-AES were $5 \%$ of relative standard deviation. All measurement data are given in Table 1. The difference in the concentration of $\mathrm{Zn}$ or Fe between one fraction and the next one corresponds to its concentration 
in the fraction range.

\section{RESULTS AND DISCUSSION}

Synthesized ferrihydrite formed aggregates, and therefore, individual ferrihydrite particles were difficult to be observed (Fig. 1a), partly because the TEM specimen was prepared by drying a droplet of the suspension solution on a TEM grid. The enlarged image indicates the presence of isolated, spherical ferrihydrite particles of 5 to $7 \mathrm{~nm}$ in diameter in the left side of Figure $1 \mathrm{~b}$ (see examples of ferrihydrite particles shown by arrows in Fig. 1b). The XRD and TEM examinations strongly suggested that nanosized ferrihydrite primary particles formed aggregates.

The size distribution of ferrihydrite aggregates was obtained from the $\mathrm{Fe}$ concentrations in the fractions by centrifugation and sedimentation (Table 1); this was calculated by $C_{\mathrm{Fe}, i}-C_{\mathrm{Fe}, i+1}$, where $C_{\mathrm{Fe}, \mathrm{i}}$ is the Fe concentration in the $i$-th fraction. The data with $\left(C_{\mathrm{Fe}, i}-C_{\mathrm{Fe}, i+1}\right) / C_{\mathrm{Fe}, i+1}<$ 0.05 , the uncertainty of ICP-AES measurements, were not used for the size-distribution calculations. The solubility of ferrihydrite is so low $\left(\log K_{\mathrm{sp}} \cong-39\right.$, Cornell and Schwertmann, 2003) that we can neglect dissolved Fe in aqueous phase. With a decrease in $\mathrm{Fe}$ concentration at similar $\mathrm{pH}$ (from 0.2 to $0.02 \mathrm{mM} \mathrm{Fe}$ corresponding to runs 1 and 2, respectively), the dominant size of ferrihydrite aggregates decreased (Figs. 2a and $2 \mathrm{~b}$ ); about $60 \%$ of aggregates were present in the $1.8-5 \mu \mathrm{m}$ fraction for

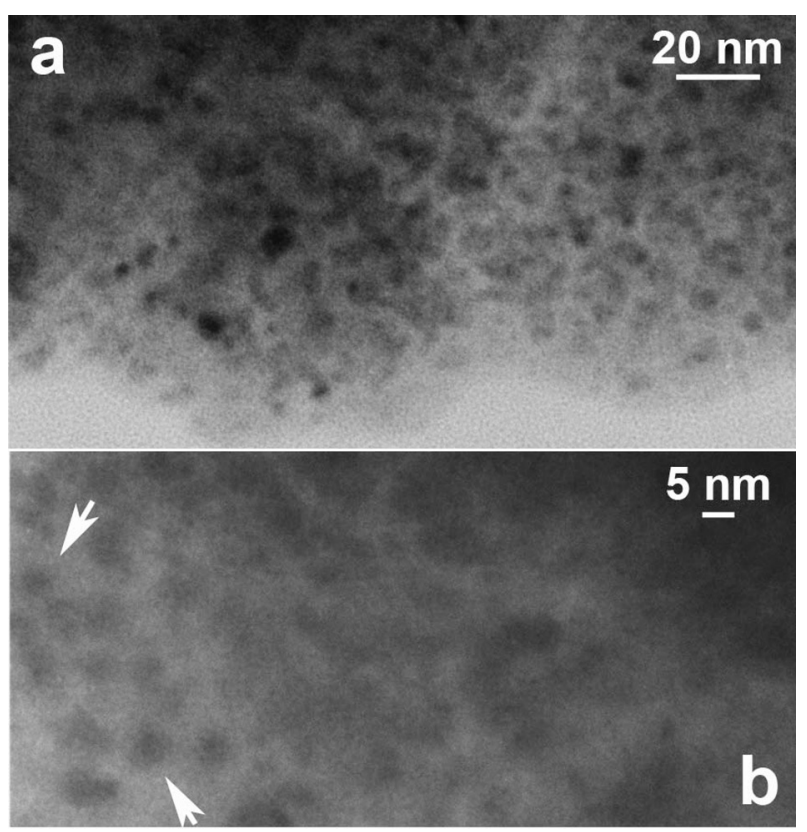

Figure 1. TEM images of ferrihydrite aggregates at relatively low (a) and high (b) magnifications. Isolated, spherical ferrihydrite particles of 5 to $7 \mathrm{~nm}$ in diameter are observed (e.g., those shown by arrows in Fig. 1b). the $0.2 \mathrm{mM}$ Fe solution while about $50 \%$ in the $0.5-1.8$ $\mu \mathrm{m}$ fraction for the $0.02 \mathrm{mM} \mathrm{Fe}$ solution. On the other hand, with a decrease in $\mathrm{pH}$ at similar $\mathrm{Fe}$ concentration (from $\mathrm{pH} 7.5$ to $\mathrm{pH} 4.2$ corresponding to runs 1 and 3, respectively), the dominant size of ferrihydrite aggregates drastically decreased (Figs. $2 \mathrm{a}$ and $2 \mathrm{c}$ ); about $70 \%$ of aggregates were present in the $<0.3 \mu \mathrm{m}$ fraction at $\mathrm{pH} 4.2$. This is consistent with the size distribution of ferrihydrite aggregates in soil where positively charged ferrihydrite at low $\mathrm{pH}$ results in aggregate instability (Rhoton et al., 2003). Our results show that the size distribution of ferrihydrite aggregates changes with chemical conditions.

We can reasonably assume that $\mathrm{Zn}$ is distributed among different-size ferrihydrite fractions as adsorbed and dissolved $\mathrm{Zn}$ (Table 1). Thus, the difference in the $\mathrm{Zn}$ concentration between the $i^{-}$and $(i+1)$-th fractions, $C_{\mathrm{Zn}, i}$ - $C_{\mathrm{Zn}, i+1}$, was thought to be the concentration of $\mathrm{Zn}$ adsorbed on ferrihydrite aggregates having the corresponding size range. In the similar way to the ferrihydrite size distribution, the data with $>0.05$ of $\left(C_{\mathrm{Zn}, i}-C_{\mathrm{Zn}, i+1}\right) / C_{\mathrm{Zn}, i+1}$ were used for the following examination for the amount of $\mathrm{Zn}$ adsorbed on ferrihydrite. We calculated the number of $\mathrm{Zn}$ atoms adsorbed on the unit surface of ferrihydrite assuming that $\mathrm{Zn}$ is adsorbed either on the surface of individual 5-nm particles or on aggregate surface. Both particles and aggregates were assumed to be spherical. A median diameter was adopted for the size of a given fraction

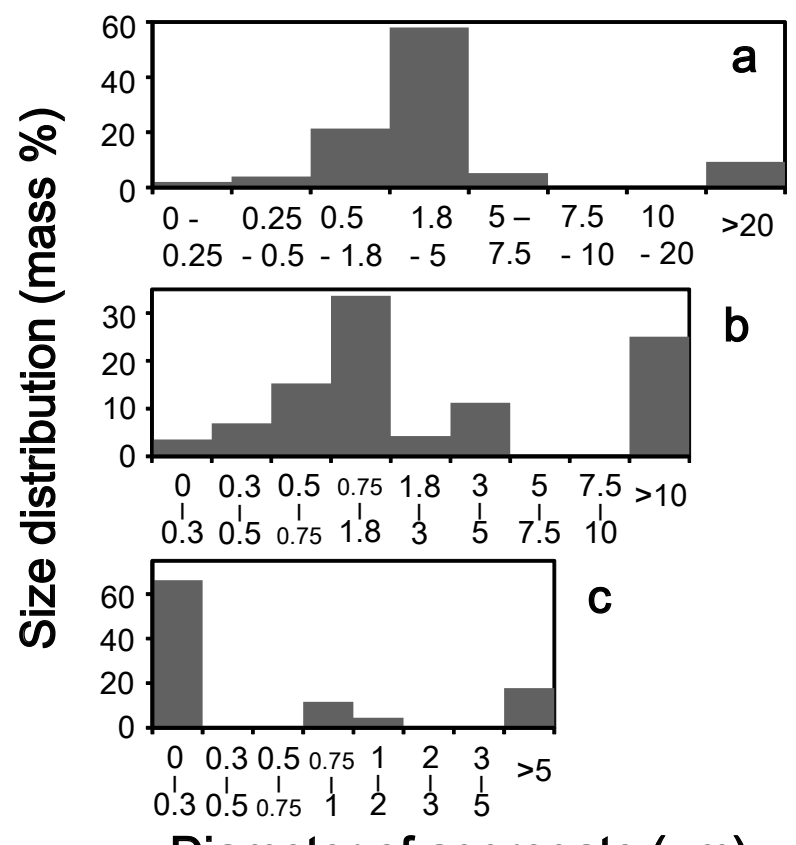

Diameter of aggregate $(\mu \mathrm{m})$

Figure 2. Variations of size distribution of ferrihydrite aggregates: (a), (b) and (c) are for runs $1(0.2 \mathrm{mM}$ of initial $\mathrm{Fe}$ and 7.5 of $\mathrm{pH}), 2(0.02 \mathrm{mM}$ and 7.0$)$ and $3(0.2 \mathrm{mM}$ and 4.2$)$, respectively, in Table 1. 
of the aggregates; for instance, the median diameter for the $<20 \mu \mathrm{m}$ fraction was $15 \mu \mathrm{m}$. The number of adsorbed $\mathrm{Zn}$ atoms per unit area $\left(\mathrm{nm}^{-2}\right)$ in a fraction is given:

Total number of $\mathrm{Zn}$ atoms

$$
\begin{aligned}
& \text { Total surface area of particles or aggregates } \\
& =\frac{M(\mathrm{Zn}) \times A / M_{\mathrm{Zn}}}{M(\mathrm{Fe}) \times 4 \pi r^{2} /\left((4 / 3) \pi r^{3} \times \rho\right)} \\
& =\frac{M(\mathrm{Zn}) \times A \times r \times \rho}{3 M(\mathrm{Fe}) \times M_{\mathrm{Zn}}} \\
& =12.15 \frac{C_{\mathrm{Zn}, i}-C_{\mathrm{Zn}, i+1}}{C_{\mathrm{Fe}, i}-C_{\mathrm{Fe}, i+1}} r
\end{aligned}
$$

where $M(\mathrm{Fe})$ and $M(\mathrm{Zn})$ are the masses of $\mathrm{Fe}$ and $\mathrm{Zn}$, respectively, in the fraction, $A$ the Avogadro number $(6.02 \times$ $\left.10^{23}\right), M_{\mathrm{Zn}}$ the atomic weight of $\mathrm{Zn}(65.4), r$ the radius of the particle or aggregate, $\rho$ the density of ferrihydrite, and $M(\mathrm{Zn}) / M(\mathrm{Fe})=\left(C_{\mathrm{Zn}, i}-C_{\mathrm{Zn}, i+1}\right) /\left(C_{\mathrm{Fe}, i}-C_{\mathrm{Fe}, i+1}\right)$. The calculated results are shown in Figure 3. The number of $\mathrm{Zn}$ atoms assumed to be adsorbed on aggregate surface increased drastically with an increase in the aggregate

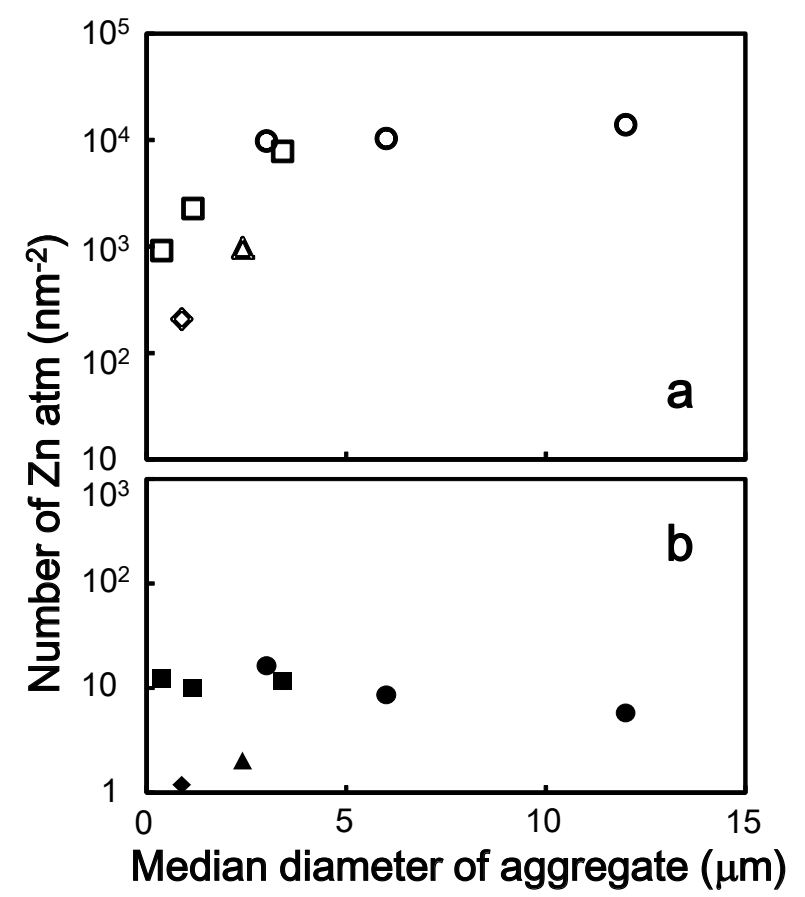

Figure 3. The number of $\mathrm{Zn}$ atoms adsorbed on ferrihydrite per unit surface as a function of median diameter of ferrihydrite aggregate (see Table 1), assuming $\mathrm{Zn}$ is adsorbed on aggregate surface (a) and on the surface of individual 5-nm particles (b). Solid and open squares, triangles, diamonds and circles corresponds to the data points of runs $1,2,3$ and 4, respectively. Note that the $\mathrm{pH}$ dependency of $\mathrm{Zn}$ adsorption can be seen in Figure $3 \mathrm{~b}$ where the number of $\mathrm{Zn}$ atoms per unit surface at $\mathrm{pH} 7.5$ (solid squares) is larger by one order of magnitude than that at $\mathrm{pH} 4.2$ (solid diamond). diameter (Fig. 3a), whereas that assumed to be adsorbed on the surfaces of individual $5-\mathrm{nm}$ ferrihydrite hardly changed with the aggregate diameter, 1 to 16 per unit surface (Fig. 3b). The small number, 1.2, for run 3 (solid diamond in Fig. 3b) was probably due to low adsorption of $\mathrm{Zn}$ at relatively low $\mathrm{pH}$ (Trivedi et al., 2004). As the ionic radius of $\mathrm{Zn}^{2+}$ is $0.083 \mathrm{~nm}$, about $40 \mathrm{Zn}^{2+}$ cations at maximum might be packed on a given unit surface. The formation of bidentate complexes of $\mathrm{Zn}$ on ferrihydrite surface (Waychunas et al., 2002) would further reduce this number. Therefore, it is impossible to pack more than hundred $\mathrm{Zn}$ atoms in the unit surface area as shown in Figure 3a. On the other hand, Dzomback and Morel (1990) suggested that ferrihydrite has 4-40 surface sites per unit surface area, and Stumm (1992) 2-12 hydroxyls per unit surface areas of oxides. These values well agree with the number of $\mathrm{Zn}$ cations that are assumed to adsorb on the surfaces of primary ferrihydrite surfaces. Thus, our results strongly indicate that $\mathrm{Zn}$ is adsorbed on the surface of individual ferrihydrite nano-particles but not on the (external) surface of ferrihydrite aggregates. This may reflect that ferrihydrite nano-particles are so loosely attached to one another in aggregates. Slight changes of the density of aggregates or the size of primary ferrihydrite particles do not affect the number of $\mathrm{Zn}$ atoms significantly (see the equation above).

For adsorption experiments, ferrihydrite is usually prepared at tens of $\mu \mathrm{M}$ to $\mathrm{mM}$ of $\mathrm{Fe}$ (e.g., Violante et al. 2003; Trivedi et al., 2004; Nagata et al., 2009), which is much larger than dissolved Fe concentration estimated from the ferrihydrite solubility (Stefansson, 2007). Although ferrihydrite forms aggregates, metal ions are adsorbed onto the surface of individual nano-particles (Fig. $3 b)$, and therefore, such adsorption experiments with high Fe concentrations will provide appropriate estimates of adsorbed amounts of metal ions. The concentration of $\mathrm{Fe}$ does not affect the estimates of adsorbed metal ions even if a suspension is filtered through a $0.2-\mu \mathrm{m}$ pore-size membrane filter because an amount of ferrihydrite aggregates with $<0.2 \mu \mathrm{m}$ is not significant (Figs. 2a and 2b). However, when adsorption experiments are carried out at low $\mathrm{pH}$, filtration of a ferrihydrite suspension with $0.2-$ or $0.4-\mu \mathrm{m}$ pore-size membrane filters will give wrong results on the amount of adsorbed metals due to the dominant size distribution at the $<0.3 \mu \mathrm{m}$ fraction (Fig. 2c).

Transport of trace metals by ferrihydrite is a complex process including adsorption, aggregation, sedimentation, transformation and co-precipitation (e.g., Buffle and Leopard, 1995; Hassellöv, and von der Kammer, 2008; Raiswell, 2011), where adsorbed metal ions can be mobilized, immobilized or remobilized, depending on the processes involved. It was reported that amorphous Fe hy- 
droxide (probably ferrihydrite) of $<50 \mathrm{~nm}$ in diameter transported $\mathrm{Pu}$ more than $3 \mathrm{~km}$ from the source area through groundwater of pH 6-8 (Novikov et al., 2006). Our results of the size distribution (Fig. 2) predict that there might be amorphous $\mathrm{Fe}$ hydroxide aggregates of larger sizes present in the upstream, which are removed from the groundwater by sedimentation in much shorter time due to the size (Tsukimura et al., 2010). Sedimentation associated with phase transformation will change the behaviors of adsorbed metal ions further. In fact, nanocrystals ( $10 \mathrm{~nm}$ in diameter) of metatorbernite, $\mathrm{Cu}$ uranyl phosphate, are found to form between goethite and hematite nano-crystals in the downstream of the Koongarra uranium mine, Australia (Murakami et al., 1997, 2005). The formation of nano-crystalline metatorbernite, called as post-adsorption phenomena, is explained as follows (Murakami et al., 1997, 2005); ferrihydrite formed by weathering adsorbs $\mathrm{U}, \mathrm{Cu}, \mathrm{P}$ and so on, is sedimented to form ferrihydrite veins and nodules, and $\mathrm{U}, \mathrm{Cu}$ and $\mathrm{P}$ are concentrated in a nano-area as the surface area is reduced by about one order of magnitude during the transformation of ferrihydrite to goethite and hematite. Finally, the concentrated $\mathrm{U}, \mathrm{Cu}$ and $\mathrm{P}$ form metatorbernite between goethite and hematite, and consequently, the U concentration in groundwater $\sim 200 \mathrm{~m}$ from the area where metatorbernite occurs decreases to $10^{-10} \mathrm{M}$ from $10^{-8} \mathrm{M}$. Our results on $\mathrm{Zn}$ adsorbed on the surface of individual ferrihydrite nano-particles strongly support the explanation although post-adsorption phenomena are possibly different between adsorbed metals.

\section{ACKNOWLEDGMENTS}

This work was partly supported by a Grant-in-Aid from the Ministry of Education, Culture, Sports, Science and Technology to TM.

\section{REFERENCES}

Antelo, J., Fiol, S., Pérez, C., Mariño, S., Arce, F., Gondar, D. and López, R. (2010) Analysis of phosphate adsorption onto ferrihydrite using the CD-MUSIC model. Journal of Colloid and Interface Science. 347, 112-119.

Buffle, J. and Leopard, G.G. (1995) Characterization of Aquatic Colloids and Macromolecules. 1. Structure and Behavior of Colloidal Material. Environmental Science \& Technology, 29, 2169-2175.

Carabante, I., Grahn, M., Holmgren, A. and Hedlund, J. (2010) In situ ATR-FTIR studies on the competitive adsorption of arsenate and phosphate on ferrihydrite. Journal of Colloid and Interface Science, 351, 523-531.

Cornell, R.M. and Schwertmann, U. (2003) The iron oxides structure, properties, reactions, occurrences and uses. pp. 664, Wiley-VCH, Weinheim, Germany.
Davis, J.A. and Leckie, J.O. (1978) Surface ionization and complexation at the oxide/water interface II. Surface properties of amorphous iron oxyhydroxide and adsorption of metal ions. Journal of Colloid and Interface Science, 67, 90-107.

Dzomback, D.A. and Morel, F.M.M. (1990) Surface Complexation Modeling: Hydrous Ferric Oxide. pp. 393, John Wiley, New York.

Hassellöv, M. and von der Kammer, F. (2008) Iron oxides as geochemical nanovectors for metal transport in soil-river systems. Elements, 4, 401-406.

Lo, B. and Waite, T. D. (2000) Structure of hydrous ferric oxide aggregates. Journal of Colloid and Interface Science, 222, 83-89.

Murakami, T., Ohnuki, T., Isobe, H. and Sato, T. (1997) Mobility of uranium during weathering. American Mineralogist, 82, 888-899.

Murakami, T., Sato, T., Ohnuki, T. and Isobe, H. (2005) Field evidence for uranium nanocrystallization and its implications for uranium transport. Chemical Geology, 221, 117-126.

Nagata, T., Fukushi, K. and Takahashi, Y. (2009) Prediction of iodide adsorption on oxides by surface complexation modeling with spectroscopic confirmation. Journal of Colloid and Interface Science, 332, 309-316.

Novikov, A.P., Kalmykov, S.N., Utsunomiya, S., Ewing, R.C., Horreard, F., Merkulov, A., Clark, S.B., Tkachev, V.V. and Myasoedov, B.F. (2006) Colloid transport of plutonium in the far-field of the Mayak Production Association, Russia. Science, 314, 638-641.

Raiswell, R. (2011) Iron transport from the continents to the open ocean: The aging-rejuvenation cycle. Elements, 7, 101-106.

Rhoton, F.E., Romkens, M.J.M., Bigham, J.M., Zobeck, T.M. and Upchurch, D.R. (2003) Ferrihydrite influence on infiltration, runoff, and soil loss. Soil Science Society of America Journal, 67, 1220-1226.

Rossberg, A., Ulrich, K.-U., Weiss, S., Tsushima, S., Hiemstra, T. and Scheinost, A.C. (2009) Identification of uranyl surface complexes on ferrihydrite: Advanced EXAFS data analysis and CD-MUSIC modeling. Environmental Science \& Technology, 43, 1400-1406.

Rout, K., Mohapatra, M. and Anand, S. (2012) 2-Line ferrihydrite: synthesis, characterization and its adsorption behaviour for removal of $\mathrm{Pb}(\mathrm{II}), \mathrm{Cd}(\mathrm{II}), \mathrm{Cu}(\mathrm{II})$ and $\mathrm{Zn}$ (II) from aqueous solutions. Dalton Transactions, 41, 3302-3312.

Scheinost, A.C., Abend, S., Pandya, K.I. and Sparks, D.L. (2001) Kinetic controls on $\mathrm{Cu}$ and $\mathrm{Pb}$ sorption by ferrihydrite. Environmental Science \& Technology, 35, 1090-1096.

Schwertmann, U. and Cornell, R.M. (2000) Iron oxides in the laboratory. pp. 188, Wiley-VCH, Weinheim, Germany.

Song, Y., Swedlund, P.J. and Singhal, N. (2008) Copper(II) and cadmium(II) sorption onto ferrihydrite in the presence of phthalic acid: Some properties of the Ternary Complex. Environmental Science \& Technology, 42, 4008-4013.

Stefansson, A. (2007) Iron(III) hydrolysis and solubility at $25{ }^{\circ} \mathrm{C}$. Environmental Science \& Technology, 41, 6117-6123.

Stumm, W. (1992) Chemistry of the solid-water interface. pp. 428, Wiley-Interscience, New York.

Towe, K. and Bradley, W.F. (1967) Mineralogical constitution of colloidal "hydrous ferric oxides." Journal of Colloid and Interface Science, 24, 384-392.

Trivedi, P., Dyer, J.A., Sparks, D.L. and Pandya, K. (2004) Mechanistic and thermodynamic interpretations of zinc sorption onto ferrihydrite. Journal of Colloid and Interface Science, 
$270,77-85$.

Tsukimura, K., Suzuki, M., Suzuki, Y. and Murakami, T. (2010) Kinetic theory of crystallization of nanoparticles. Crystal Growth \& Design, 10, 3596-3607.

Violante, A., Ricciardella, M., and Pigna, M. (2003) Adsorption of heavy metals on mixed $\mathrm{Fe}-\mathrm{Al}$ oxides in the absence or presence of organic ligands. Water, Air, \& Soil Pollution, 145, 289-306.

Waychunas, G.A., Fuller, C.C. and Davis, J.A. (2002) Surface complexation and precipitate geometry for aqueous $\mathrm{Zn}$ (II) sorption on ferrihydrite I: X-ray absorption extended fine structure spectroscopy analysis. Geochimica et Cosmochimica Acta, 66, 1119-1137.

Manuscript received June 18, 2012

Manuscript accepted October 10, 2012

Published online December 1, 2012

Manuscript handled by Tsutomu Sato 